\title{
Evaluating a proposed retrofit measure for a multi-unit residential building which uses an air-source heat pump operating in an enclosed balcony space
}

\author{
Touchie, Marianne F., Pressnail, Kim D. \\ Version Post-print/accepted manuscript \\ Citation Touchie, Marianne F., and Pressnail, Kim D. (2014). Evaluating a \\ (published version) proposed retrofit measure for a multi-unit residential building which \\ uses an air-source heat pump operating in an enclosed balcony space. \\ Energy and Buildings 85, pp. 107-114. \\ Additional publisher The final version of this article is available from Elsevier at \\ information https://doi.org/10.1016/j.enbuild.2014.08.048 \\ Copyright/License (c) $\ominus$ This work is licensed under the Creative Commons \\ BY NC ND Attribution-NonCommercial-NoDerivatives 4.0 \\ International License. To view a copy of this license, visit \\ http://creativecommons.org/licenses/by-nc-nd/4.0/.
}

How to cite TSpace items

Always cite the published version, so the author(s) will receive recognition through services that track citation counts, e.g. Scopus. If you need to cite the page number of the author manuscript from TSpace because you cannot access the published version, then cite the TSpace version in addition to the published version using the permanent URI (handle) found on the record page.

This article was made openly accessible by $U$ of $T$ Faculty. Please tell us how this access benefits you. Your story matters. 
Evaluating a Proposed Retrofit Measure for a Multi-Unit Residential Building which Uses an Air-Source Heat Pump Operating in an Enclosed Balcony Space

Marianne F. Touchie (corresponding author), Department of Civil Engineering, University of Toronto

Kim D. Pressnail, Department of Civil Engineering, University of Toronto

Corresponding author contact details: +14166686408 , marianne.touchie@mail.utoronto.ca. Department of Civil

Engineering, University of Toronto, 35 St. George Street, Toronto, Ontario, Canada, M5S1A4

\section{Abstract:}

To improve the energy performance of Toronto's post-war multi-unit residential buildings (MURBs), these buildings must be energy retrofitted. Here, a novel energy retrofit strategy employing air-source heat pumps (ASHPs) operating in enclosed balcony spaces is assessed. The enclosed balcony provides a thermal buffer zone (TBZ) which can improve the coefficient of performance of the ASHP compared to typical exterior operation by accessing captured solar gains. The estimated energy savings associated with implementing this retrofit strategy was determined using a hybrid modeling approach. A calibrated energy model of a 1968 MURB represented the base case energy consumption. Then, a supplementary algorithm, developed based on laboratory testing, was used to determine the quantity of energy that could be extracted from the TBZ and delivered to the north- and south-facing suites as well as to hot water storage. The modeling exercise yielded estimated whole-building energy and greenhouse gas emissions savings of $39 \%$ and $45 \%$, respectively. Due to utility prices at the time of writing, the energy cost savings do not present a compelling financial case. However, the qualitative benefits of this retrofit strategy include suite-based control for occupants and the ability to sub-meter space heating energy use at the suite-level.

Key words: multi-unit residential buildings, energy modeling, balcony enclosure, air-source heat pump, retrofit

\section{Introduction}

Post-war multi-unit residential buildings (MURBs) in the City of Toronto are important municipal housing assets yet the energy used in heating these buildings presents a significant environmental burden [1][2]. Toronto MURBs 
comprise an estimated $55 \%$ of the dwelling units in the city and these buildings, in 2004 , were responsible for $2.6 \mathrm{M}$ tonnes of equivalent carbon dioxide $\left(\mathrm{eCO}_{2}\right)[1]$. To lessen this environmental burden while preserving this important housing stock, these buildings must be energy retrofitted.

One reason why these MURBs have high energy intensities is related to space conditioning. Many of these buildings are heated with perimeter hydronic or electric radiators and feature a pressurized-corridor ventilation system. Typically there is no central air-conditioning. Instead window air-conditioning units are installed in some or all of the suites. In-suite radiator controls are often disabled so occupants often have little control over their suite temperature. During the winter, occupants attempt to regulate the suite temperature by using supplementary heaters as needed. In suites above the neutral pressure plane, occupants often open their windows [3] either for temperature control or for access to outside air. While excessive energy-use results from envelopes that leak air, this problem is aggravated by the uncontrolled air leakage associated with opening windows. With uncontrolled air leakage and the effect of stack action, suites tend to be over-or under-ventilated. With poor circulation of fresh air [4], indoor air quality may suffer as well. In some MURBs, the mechanical equipment used to supply space heating and ventilation is original to the building, which can result in reduced energy efficiency due to equipment age. However, as the original mechanical systems reach the end of their design service life, there is an opportunity to change the way the buildings' systems function.

This paper describes a novel MURB energy retrofit strategy involving a suite-based air-source heat pump (ASHP) operating in an enclosed balcony space which serves as a thermal buffer zone (TBZ). The strategy was adapted from an idea originally developed for single family homes called Nested Thermal Envelope Design ${ }^{\mathrm{TM}}$ (NTED $\left.{ }^{\mathrm{TM}}\right)$ [5] which involves the use of two independently controlled zones: a core zone and a thermal buffer zone.

The proposed retrofit strategy contemplated in this paper includes replacing the central space heating equipment in a MURB with suite-based mini split ASHPs to provide demand-based space conditioning. However, ASHPs have not been widely adopted for heating in colder climates because the coefficient of performance (COP) is lower when outdoor temperatures are colder. If the exterior unit of the ASHP could be kept at a higher temperature than ambient, higher COPs could be maintained. One opportunity, unique to MURBs, is to make use of the 
existing balcony space as a TBZ. By enclosing the unconditioned balcony, a volume of air, heated by passive solar gains and heat losses from the apartment, can be used to increase the COP of the ASHP. The TBZ is created by installing a retractable enclosure for the existing balcony space. The purpose of the TBZ is to capture passive solar gains and then use the ASHP to transfer this energy to the suites in a controlled manner. As such, the retractable balcony enclosure modeled in this work is primarily glass to maximize the solar gains to the space.

Of course, exposure to solar radiation varies according to suite orientation. A south-facing suite in Toronto will see a significantly lower heating load than a north-facing suite due to the space heating benefit of the incident solar radiation. However, uncontrolled solar gains can also result in overheating of the south-facing suites [6]. This overheating can lead to occupants opening windows and, consequently, increased energy losses due to uncontrolled air movement. The idea of transferring solar gains from the south to the north side of an apartment building has been explored previously. Melih [7] investigated the passive transfer of warm air from a south-facing sunspace through ducts to the north-side of an apartment building. Here, the innovation is to provide inter-suite heat transfer assisted by an ASHP. The proposed retrofit would involve the use of a multi-head heat pump that can transfer heat from the south side TBZ to the north and south side of the building as well as to hot water storage. This measure can lead to a reduction in the instance of overheating on the south façade while providing the north-facing suites with more equitable access to the space heating benefits of solar gains.

As Toronto is a heating-dominated climate (previous 10-year average heating degree days: 3390 and cooling degree days 400 [8]), the focus of this work is on the space heating case. In the summer, the retractable enclosure can be opened to restore the pre-retrofit open air balcony. Then, the ASHP would function as an air conditioner, moving heat from the suite to the exterior.

\section{Modeled Scenarios}

The objective of this work was to estimate the impact of retrofitting a centrally-heated MURB with suite-based ASHPs operating in TBZs. However, it is useful to present the projected energy savings in the context of other incremental improvements to the building envelope and heating, ventilating and air-conditioning (HVAC) system. For example, while the proposed retrofit solution includes an ASHP operating in an enclosed balcony, it is 
important to recognize the energy benefit of simply enclosing a balcony space or switching from electric resistance heating to an ASHP. Furthermore, the combined effects of the ASHP $\mathrm{EXT}_{\text {and }}$ and the TBZ were examined to isolate the benefit of operating an ASHP in hybrid mode depending on the TBZ conditions. The scenarios modeled are presented in Table 1.

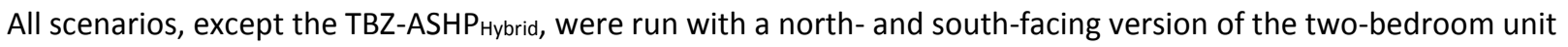
shown in Figure 1. The two orientations were modeled to identify the impact of solar gains. The TBZ-ASHPHybrid was only tested on the south side because of the requirement for solar gains. For this case, the TBZ was cooled to various set point temperatures. This range of TBZ temperatures was tested because the net heat removed by the ASHP is dependent on the lowest TBZ temperature allowed by the ASHP control algorithm. All TBZ set points, shown in Table 2, were between the interior apartment temperature ( $\left.T_{A P T}\right)$ and the exterior temperature ( $\left.T_{E X T}\right)$. As shown, the TBZ set point temperatures are a function of the apartment (interior) and exterior air temperatures.

\section{Modeling Approach}

Limitations in the available energy modeling software required the development of a building-level model, a suitelevel model and a model output processor to determine the estimated MURB energy consumption for each of the retrofit scenarios presented in Section 2. These three components of the modeling exercise and how the resulting data were merged are described in Sections 3.1, 3.2 and 3.3.

While this work focuses on the modeled impacts of the proposed retrofits, this modeling was based on the results of both field monitoring and laboratory testing. The performance of the base case building-level model was determined from data collected from an occupied MURB over the course of one year [6]. Development of the model output processor was informed by laboratory testing of a suite-based ASHP operating in an enclosed balcony space. The data collected were used to determine how the COP would change with the balcony space temperature. 


\subsection{Building Model}

In previous work by the authors [6], a calibrated energy model was developed for a subject MURB constructed in 1968. The MURB on which this model was based exhibited many of the characteristics common to other post-war MURBs including exposed slab edges, pressurized-corridor make-up air supply, hydronic baseboard heating and no central air-conditioning. eQUEST (version 3.64), an hourly simulation program, was used to develop a model of the MURB. The model was then calibrated using energy consumption data, local weather data, and interior condition data collected during a one-year monitoring period of the subject MURB. However, the eQUEST model could not simulate the operation of an ASHP between two confined spaces and it did not generate realistic temperatures within the enclosed balcony sunspace [9]. To address these modeling issues, a suite-level model was used to generate appropriate TBZ temperatures and to determine the suite-based space heating requirements. Then, a model output processor was developed to simulate the effects of the ASHP operating between the TBZ and the suites.

\subsection{Suite Model}

A suite-level model based on a two-bedroom suite in the subject MURB was generated using EnergyPlus (version 8.0.0). The OpenStudio Trimble Plug-in (version 0.15.0.10520) for SketchUp (version 8.0.16846) was used to set up the geometry and the thermal zones, as shown in Figure 1.

This suite-level EnergyPlus model was then calibrated to the heat gains and losses of an identical two-bedroom suite zone in the eQUEST model that had been calibrated using the monitored data. A comparison between the heat gain and loss components of each model is presented in Figure 2 . The difference in the sum of the total heat losses was less than $2 \%$ and the difference between the sum of the total heat gains was less than $1 \%$.

Both a north and south version of the suite-level model were run with a local weather file generated from the data collected from the subject MURB and were used to determine the suite-level space heating requirements. Then, the south-facing suite model, run with a one-minute time step, was used to determine the heat available for removal from the TBZ by the ASHP which is a function of solar gains and the heat gains and losses to and from the 
TBZ. When there is not enough heat to extract from the TBZ, the ASHP draws air from the exterior, operating at a lower COP as described in Section 3.3.

The first step in determining how much heat could be removed from the TBZ was to quantify the effective solar gains transmitted to the TBZ. The term "effective" is used to denote the solar gains available to the ASHP after accounting for the losses due to air leakage from the TBZ to the exterior. For these reasons, the instantaneous effective solar gains are often lower than the instantaneous solar radiation transmitted through the TBZ window in the EnergyPlus model output. The effective solar gains ( $q_{\text {solar,eff }}$ ) were determined using Equation 1 which conducts an energy balance on the TBZ using the heat flows in and out of the TBZ (q flows into and out of the TBZ were determined from the output of the EnergyPlus model run with a floating TBZ temperature. Equation 1 was then rearranged to solve for the effective solar gains.

Equation 1

$q_{\text {solar,eff }}+q_{T B Z, A P T}+q_{T B Z, E X T}=0$

where:

$q_{\text {solar,eff }}=$ effective solar gains $[W]$

$q_{T B Z, A P T}=$ heat flow from Apartment to TBZ when TBZ temperature is floating $[W]$

$q_{\text {TBZ.EXT }}=$ heat flow from Exterior to TBZ when TBZ temperature is floating $[W]$

With the effective solar gains established, the next step was to determine the heat available to be pumped from the TBZ or qavail. When heating is required in the apartment and there are sufficient gains to the TBZ, the ASHP removes energy from the TBZ. This effect was achieved by cooling the TBZ to a set point temperature using the ZoneHVAC:IdealAirLoadsSystem object in EnergyPlus [10]. The effective solar gains from the floating TBZ temperature case were then combined with the resulting heat flows from the cooled TBZ case (denoted by the prime symbol) to quantify the amount of heat available to the ASHP, as shown in Equation 2.

Equation 2 
$q_{\text {solar }, e f f}+q_{T B Z \prime, A P T}^{\prime}+q_{T B Z \prime, E X T}^{\prime}=q_{\text {avail }}$

where:

${q^{\prime}}_{T B Z^{\prime}, A P T}=$ heat flow from Apartment to TBZ when TBZ is cooled $[W]$

$q_{T B Z^{\prime}, E X T}^{\prime}=$ heat flow from Exterior to TBZ when $T B Z$ is cooled $[W]$

$q_{\text {avail }}=$ heat available to be pumped by ASHP from $T B Z[W]$

However, as the TBZ temperature is drawn down below the apartment temperature with operation of the ASHP, the heat loss from the apartment to the TBZ increases. Figure 3 shows this effect on the TBZ temperatures and associated heating loads by comparing two suite-based models for one week in January: one with electric baseboard heating and one with the ASHP operating in the TBZ drawing down the temperature.

The case where the ASHP draws down the TBZ temperature below the apartment temperature cannot be directly compared to the electric heating case because the resulting apartment heating load is different, as shown in Figure 3. To ensure a like-to-like comparison between the cases, the additional heat load in the apartment must be taken into account. This was done by returning a proportion of the qavail to the apartment which was equal to the increased heating load when the TBZ temperature is drawn down ( $\left.q^{\prime}{ }^{\top}{ }^{\prime} z^{\prime}, T B Z\right)$. Therefore, the net heat pumped by the ASHP from the TBZ ( $q_{p}$, TBZ,Total) is determined by Equation 3.

Equation 3

$q_{p, T B Z, T o t a l}=q_{\text {avail }}-q_{T B Z \prime, T B Z}^{\prime}$

where:

$q_{p, T B Z, T o t a l}=$ net heat pumped by ASHP from $T B Z[W]$

$q_{T B Z^{\prime}, T B Z}^{\prime}=$ additional heat flow from Apartment to TBZ when TBZ is cooled $[W]$

Calculation of this net heat pumped and the associated energy required for pumping is important to directly compare the ASHP heating system efficiency with the electric baseboard case. The appropriate COP based on the 
TBZ or exterior temperature is applied to the net heat pumped and the heat returned to the apartment by the model output processor described below.

\subsection{Model Output Processor}

Next, a spreadsheet program was used to process the one-minute interval output from the suite-level model. Laboratory testing [11] showed that operation of the ASHP inside a TBZ is only advantageous when the rate at which passive solar gains enter the space exceeds the rate at which heat is extracted. When available, excess heat from the south side TBZ can be used to meet the space heating loads of the north- and south-facing suites. For periods when the solar gains exceed the space heating requirements of both the north and the south suites, the excess heat pumped by the heat pump can be directed to hot water storage for use at a later time. During periods without sufficient solar gains, the ASHP can draw heat directly from the exterior. This dual function ASHP, termed

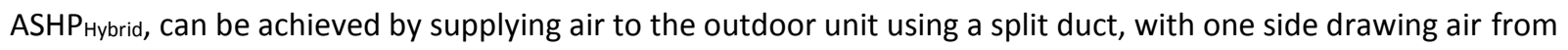
the TBZ and the other drawing air from the exterior. A controller could then be used to operate a motorized damper that changes the air source depending on the temperature differential between the TBZ and the exterior. As both the exterior and the TBZ temperature cause the COP of the ASHP to approach unity when the exterior temperature drops, an electric resistance heater provides back-up heating. When the north suite is not receiving

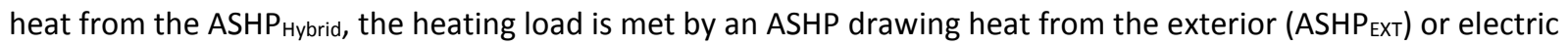
resistance heating. Figure 4 summarizes this control algorithm.

The COP of the ASHPEXT and the ASHPHybrid were determined by Equation 4, which was derived from the laboratory testing of the retrofit strategy [11] using a low-temperature heat pump. Equation 4 describes how the COP of the ASHP changes with the ambient temperature which is also shown in Figure 5.

Equation 4

$C O P=0.069 T_{a m b}+2.24$

where:

COP $=$ coefficient of performance of the ASHP 
$T_{a m b}=$ ambient temperature surrounding the outdoor unit $\left[{ }^{\circ} \mathrm{C}\right]$

Once the COP had been calculated using Equation 4, it was used to determine the relationship between the power required by the ASHP for pumping and the total heat delivered by the interior unit as shown in Equation 5 and Equation 6.

Equation 5

$\mathrm{COP}=\frac{q_{d}}{q_{\text {Power }}}$

Equation 6

$q_{d}=q_{p}+q_{\text {Power }}$

where:

$q_{d}=$ heat delivered by ASHP $[W]$

$q_{\text {Power }}=$ electrical power required by ASHP $[W]$

$q_{p}=$ heat energy extracted or pumped by ASHP $[W]$

Following determination of the heat removed from the TBZ and delivered to the north and south suites, as well as hot water storage, the power required by the heat pump was calculated from the COP equations presented here. Finally, these power consumption values were compared with the base case model energy consumption to determine suite-level energy-use reduction factors. These reduction factors were then applied to the space heating and domestic hot water (DHW) loads from the calibrated building-level eQUEST energy model.

\section{Results and discussion}

Given the hybrid nature of the modeling approach, the results are presented at both the suite- and building-level.

\subsection{Suite Modeling}

The ASHP Hybrid, modeled using the model output processing algorithm, operates at different times to supply different loads: south space heating; north space heating; and excess heat directed to hot water storage. As the 


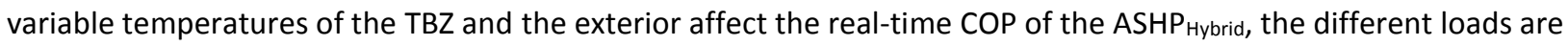
provided with different overall COPs in a heating season. For example, the ASHP Hybrid only draws heat from the TBZ when it is advantageous compared to drawing heat from the exterior. This occurs most often during periods of solar gain. During these solar gain periods, the south suite heating loads are often minimal, so almost all of the heat removed from the TBZ goes to the north side or to hot water storage. This also means that the average COP, when heat is pumped to the north side and hot water storage, is higher. To determine the COP of each component of the heat delivered, an overall COP based on the total seasonal performance was determined. The Overall COP was calculated by dividing the total heat delivered by total power drawn. To demonstrate the differences in COP, a bubble plot of the heating energy delivered to the south-facing suite is shown in Figure 6 and for the north-facing suite in Figure 7. The area of the bubbles is proportional to the total heat delivered while the bubble position along the y-axis indicates the Overall COP at which it was pumped.

As shown in Figure 6, the electric resistance heating in the base case, and the back-up electric resistance heating in the ASHP cases, is supplied at $100 \%$ efficiency, resulting in a COP of 1 . In Figure 6 , the performance of the ASHP $_{\text {Hybrid }}$ is split into two components: ASHP cooler TBZ temperatures, the average ASHP ${ }_{E X T}$ COP increases and the average ASHP $\mathrm{PBZ}_{\mathrm{T}}$ COP decreases. There are a few influencing factors here. First, by drawing the temperature of the TBZ down to equal the exterior temperature, the insulating effect of the TBZ is essentially negated. This, in turn, increases the south suite space heating load which corresponds to the larger bubble sizes. As the temperature in the TBZ is drawn down to a lower setpoint, the ASHP or, in other words, during periods of extreme cold with solar gains to the TBZ. Therefore, if the ASHPTBZ is providing a greater proportion of the south suite heating, the ASHPEXT provides less and is operating at warmer average temperatures which yield a higher overall COP.

Note the relatively small proportion of heat delivered by the ASHPTBz in Figure 6. This is because almost all heat drawn from the TBZ occurs during periods of excessive solar gains on the south side of the building. This means that most of the heat removed from the TBZ is delivered to the north-facing suite, shown in Figure 7, and to the hot water storage. 
By determining the Overall COP based on the total heat delivered by the ASHP Hybrid System, the "Low" temperature case is considered the optimal TBZ operating condition. ASHPHybrid will refer to this low temperature setting for the remainder of the paper.

Figure 8 shows the total energy consumption for one north- and one south-facing suite for each of the modeled scenarios. While the TBZ temperature drawdown during ASHP Hybrid operation increases the south suite-heating load, this increased load is offset by excess solar gains being captured in hot water storage. Therefore, it is only when the impact of the retrofit measure on both space heating energy consumption and hot water storage derived from solar gains are examined together that the benefit of capturing this heat from the TBZ is realized. To show the influence of the amount of heat pumped to hot water storage, a balance line indicating the net energy consumed in the proposed retrofit strategy is depicted in Figure 8. Table 3 shows the space heating energy-use reduction factors based on the energy consumption of each modeled scenario in Figure 8.

\subsection{Building Modeling}

The suite-level energy reduction factors associated with the contemplated retrofits are limited to space heating and so were only applied to this part of the whole-building model output. The reduction factors obviously differ between the suites on the north and south facades, as shown in Table 3. Since there are an equal amount of suites on each façade in the subject MURB, these factors were simply averaged together and multiplied by the total annual space heating energy consumption in the whole-building model.

An estimate of the excess heat available for hot water storage was made based on the number of suites in the building and the total kilowatt-hours of excess heat per south-facing suite as determined by the model output processing algorithm.

The results which follow, are presented in terms of energy savings, energy cost savings, and reduction in greenhouse gas (GHG) emissions. These metrics were used because the decision to pursue a building energy retrofit can include any one or perhaps all of these measures. Energy cost savings can be a major driver as these savings are used to offset the capital cost of the retrofit measures. Furthermore, adherence to codes, local 
building standards or incentive programs can require a measure of absolute energy saved or GHG emissions avoided. As such, the results of this work should be viewed through all three lenses.

Figure 9 shows the total annual building-level energy intensity of the two retrofits yielding the greatest suite-level savings compared to the base case. Both retrofit cases shown include a TBZ but one case has ASHPs operating exclusively with the exterior air (TBZ-ASHP $\left.{ }_{\mathrm{EXT}}\right)$ and the other operates in hybrid mode (TBZ-ASHP $\mathrm{Hybrid}_{\text {). }}$

These energy savings, which are determined on the site level, are a combination of the reduced heating load by enclosing the balcony space, the improvement in the COP of the ASHP, the efficiency gains inherent in the switch from natural gas to electricity (95\% efficient natural gas boiler compared to an ASHP with an overall COP of approximately 2) and a small reduction in the electricity used for the pumps in the hydronic heating system.

Given the greater cost of electricity compared to natural gas per kilowatt-hour at the time of writing [12][13], the reduction in energy consumption does not translate to a comparable decrease in energy cost. For example, the total annual energy cost for the subject building prior to the retrofit is approximately $\$ 370,000$. Due to the fuel switch from relatively inexpensive natural gas $\left(\$ 0.24 / \mathrm{m}^{3}\right.$ or approximately $\left.\$ 0.023 / \mathrm{ekWh}\right)$ to electricity $(\$ 0.11 / \mathrm{kwh})$, the resulting annual energy cost savings is only $\$ 10,000$ or less than $3 \%$ of the total pre-retrofit utility cost. However, in the future, if utility pricing reflects the GHG emissions impact associated with the particular energy source, the case for the TBZ-ASHP retrofits based on energy cost savings would become more compelling as shown in Figure 10.

At the time of writing, the GHG emissions factor for natural gas was 1.6 times that of electricity in the City of Toronto, based on an equivalent kilowatt-hour. This determination is based on factors of $0.11 \mathrm{~kg} \mathrm{eCO} / \mathrm{kwh} \mathrm{of}$ electricity and $1.891 \mathrm{~kg} \mathrm{eCO}_{2} / \mathrm{m}^{3}$ of natural gas [14] assuming $10.3 \mathrm{ekWh} / \mathrm{m}^{3}$. This means that natural gas use has a greater impact on the atmosphere per equivalent kilowatt-hour than electricity use. So, the impact of the retrofits on the building GHG emissions is proportionally greater than the reduction in equivalent kilowatt-hours. However the impact of fuel switching on GHG emissions would vary depending on the location of the building. Other provinces which include a relatively large number of MURBs in their building stock are British Columbia (0.014kg

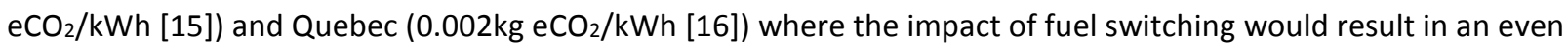


greater reduction in GHG emissions and Alberta $\left(0.88 \mathrm{~kg} \mathrm{eCO}_{2} / \mathrm{kWh}\right.$ [16]) where the impact of fuel switching would be significantly less.

\subsection{Other Retrofit Consequences}

The results of the proposed retrofit measure have been presented in terms of the potential energy savings, energy cost savings, and GHG emission avoidance. While these savings are readily quantifiable with the energy models and the model output processing algorithm, the proposed retrofit measure does not function in isolation. Buildings are complex systems and the retrofit contemplated in this work must be viewed in the context of the rest of the building and the occupants. There are a number of qualitative benefits that can be realized by implementing the proposed retrofit measure, though some of these benefits require further modifications to the building to achieve the maximum impact. However, ASHPs are also complicated systems which require appropriate sizing, installation, control and maintenance in order to function at maximum efficiency.

A suite-based conditioning system with in-suite controls, such as the proposed retrofit, would allow occupants to adjust the suite set point temperature as desired. With greater control over the temperature of their suite, occupants may choose to open windows less frequently for temperature regulation. However, to minimize the heating load differential between suites at the top and the bottom of the building due to stack action, the suites should be compartmentalized. This can be achieved through interior air sealing between suites and along vertical chases in the building. To some extent, these suite-based systems can also limit the overheating which can occur in a centrally-heated system by not providing heat to a space that has exceeded the set point temperature.

To further reduce loads, occupancy sensors can be used to lower set point temperatures and air flow rates when occupants are away. Further, with the suite-based equipment connected to the suite circuit, occupants could be billed directly for their energy-use rather than bulk-billing which is common in buildings with centralized systems. There have been numerous studies showing that shifting the financial responsibility for energy-use from building owners to occupants can significantly reduce energy-use [17].

There are many positive aspects to switching from a centralized space conditioning system to a suite-based system but the challenges of operating an ASHP to maximize efficiency and occupant comfort must also be recognized. 
'Cold blow' is a term used to describe the flow of air from the indoor unit of the ASHP before the coils have warmed sufficiently [18]. This can be uncomfortable for occupants during the heating season. To mitigate this issue and to ensure the provision of heat even when outdoor temperatures are low, an electric resistance back-up heater is included as part of the indoor unit [18] of the ASHP. The operation of this resistance heating (COP=1) obviously has a negative effect on the overall COP of the ASHP and must be minimized. Further, other issues such as improper equipment sizing, refrigerant flow, and refrigerant pipe length can also negatively impact COP. The ASHP would also take up usable floor space on the balcony but by operating the ASHP within the thermal buffer zone, the heat exchanger surfaces may see less dirt and debris build-up over time possibly improving the COP compared to a typical installation.

The proposed TBZ-ASHP Hybrid retrofit shows promise as a retrofit strategy that can reduce energy consumption in cold-climate MURBs along with the associated GHG emissions. Furthermore, there are potential benefits for the occupants in terms of comfort and controllability. To maximize the energy savings benefits of TBZ-ASHPHybrid retrofit, operational characteristics of the ASHP as well as other aspects of the building operation must be considered, as discussed.

\section{Conclusions and Future Work}

This paper presented the energy, energy cost and GHG emissions impacts of applying the proposed energy retrofit strategy to the subject MURB. The building-level energy model was generated using data collected from an occupied MURB over a one year period. The model of the ASHP was validated based on laboratory testing of an ASHP operating in an enclosed balcony space. Using this hybrid energy modeling approach supplemented by a model output processor, the key findings of this work are as follows:

1. The proposed retrofit measure can be used to capture excess solar heat gain to offset north suite heating and

DHW loads as well as reduce overheating of the south-facing suite;

2. The estimated impacts of the proposed retrofit measure include reductions in the annual energy intensity of the subject MURB by $39 \%$ and the associated GHG emissions by $45 \%$ (based on emissions factors from Toronto, Canada); 
3. Given the current cost of energy, this retrofit strategy could not likely be justified based on the energy cost savings alone. However, if future utility prices are proportional to the GHG emissions of natural gas and electricity on an equivalent kilowatt-hour basis, the case for energy cost savings becomes more compelling.

Aspects of the proposed retrofit strategy that require further consideration include refinement of the energy model and testing of a prototype, the addition of hygrothermal modeling to assess condensation potential, the assessment of the performance in different building configurations and an estimate of the implementation cost.

To appropriately model the variable-speed ASHP operating in the TBZ as well as model multiple zones with the TBZ-ASHP Hybrid arrangement, which would require variable refrigerant flow, access to an energy modeling program with greater functionality is required. With a fully functional model, the cooling case can also be easily tested. A hygrothermal assessment of the new double envelope arrangement is also required to determine the condensation potential in the TBZ throughout the year. Of particular concern is the occupants' ability to open the window between the apartment and the TBZ during winter allowing warm moist air to enter the colder zone.

Continued overheating of the south-facing suite, even after drawing the TBZ temperature below the exterior temperature, means there is still excess heat that can be used. Strategies and technologies for moving this heat easily from the south- to the north-side of the building should be investigated.

While the retrofit measure has been modeled on re-entrant balconies in the subject building, this approach should be explored for balconies which project beyond the building envelope which are also common in Toronto MURBs.

Finally, a detailed estimate of the TBZ enclosure and ASHP equipment and installation cost is required. Ideally this would be compared with the cost to replace existing, aging HVAC equipment and offset against a projected increase in rental income and future energy prices.

\section{Acknowledgements}

The authors gratefully acknowledge the assistance the funding provided by the Natural Sciences and Engineering Research Council (NSERC) and the Neil B. Hutcheon Bequest. 


\section{References}

[1] Touchie, M.F., Binkley, C, Pressnail, K.D. “Correlating Energy Consumption with Multi-Unit Residential Building Characteristics in the City of Toronto," Energy and Buildings 66 (2013) pp.648-656.

[2] Stewart, G., Thorne, J., Tower neighbourhood renewal in the greater golden horseshoe: An analysis of high-rise tower apartment neighbourhoods developed in the post-war boom (1946-1984) 2010. [Online] Accessed: July 2011. Available: http://www.cugr.ca/tnrggh

[3] Jian, Y., Guo, Y., Liu, J., Bai, Z., Li, Q., Case study of window opening behaviour using field measurement results, Building Simulation, 4 (2011) 107-116.

[4] United Way. Vertical Poverty: Poverty by Postal Code 2. United Way Toronto. 2011. pp. 62-67.

[5] Dixon, E., Richman, R., Pressnail, K.D. and Touchie, M.F. NTED ${ }^{\text {TM}: ~ A n ~ I n n o v a t i v e ~ D e s i g n ~ U s i n g ~ N e s t e d ~ T h e r m a l ~}$ Envelopes to Achieve Significant Reductions in Energy Use, in Proc. Thermal Performance of Exterior Envelopes of Whole Buildings XI International Conference, Clearwater Beach, FL, 2010

[6] Touchie, M.F., Pressnail, K.D. “Using Suite Energy-Use and Interior Condition Data to Improve Energy Modeling of a 1960’s Multi-Unit Residential Building," Energy and Buildings (In Press)

[7] Melih, T., Opposite sunspace passive solar air heating system. Solar Energy. March 1997. 60(3-4) pp. 127-134

[8] Environment Canada. 2013. [Online] Accessed: October 2013. Available: http://climate.weather.gc.ca/

[9] Gutermann, A., Eggenberger, A., Comfort and energy savings potential of different sunspace designs. ISES Solar World Congress, 1987.

[10] U. S. Department of Energy, EnergyPlus Input Output Reference, 2013. [Online] Accessed June 2013. Available: http://apps1.eere.energy.gov/buildings/energyplus/pdfs/inputoutputreference.pdf

[11] Touchie, M.F., Pressnail, K.D. "Testing and Simulation of a Low-Temperature Air-Source Heat Pump in a Thermal Buffer Zone," Energy and Buildings 75 (2014) pp.149-159. 
[12] Toronto Hydro. Electricity Rates and Charges. 2013 [Online] Accessed: November 2013. Available:

http://www.torontohydro.com/sites/electricsystem/residential/yourbilloverview/Pages/ElectricityRates.aspx\#suit emeter

[13] Enbridge. Purchasing Gas from Enbridge. 2013. [Online] Accessed: November 2013. Available:

https://www.enbridgegas.com/homes/accounts-billing/residential-gas-rates/purchasing-gas-from-enbridge.aspx

[14] Toronto Atmospheric Fund, Emission Quantification. 2013. [Online] Accessed: October 2013. Available:

http://www.toronto.ca/taf/quant_policy_approach.htm

[15] British Columbia Ministry of Environment. 2013 B.C. Best Practices Methodology for Quantifying Green House Gas Emissions. 2013. [Online] Accessed: August 2014. Available:

http://www.env.gov.bc.ca/cas/mitigation/pdfs/BC-Best-Practices-Methodology-for-Quantifying-Greenhouse-GasEmissions.pdf

[16] High Performance Solutions Inc. Emission Factors Canada. 2009. [Online] Accessed: August 2014. Available: http://www.partnersinprojectgreen.com/files/Programs/Carbon101/Carbon Emission Factors.pdf

[17] Dewees, D., Tombe, T, The Impact of Sub-Metering on Condominium Electricity Demand. Canadian Public Policy. Vol. XXXVI, No. 4, 2001.

[18] Lubliner, M., Andrews, J., Baylon, D., Heating with Residential Heat Pumps. ASHRAE Journal. 47.10 (2005) 36-

$40,42-43$ 